\title{
Causes of Non-maternal Mortality in Taiwan
}

\author{
Senyeong Kao, Ph D, Li-Mei Chen, MPH, MSPH, Leiyu Shi, Dr PH, Martin C Weinrich, Ph D and \\ C Arden Miller, MD
}

\begin{abstract}
This study identifies the major causes of non-maternal mortality in Taiwan. The study findings may enbance current information regarding non-maternal mortality and bave important implications for future legislation.
\end{abstract}

Key words: Taiwan; non-maternal death; pregnancy-related mortality; information

\section{Introduction}

Pregnancy-related deaths include both maternal and nonmaternal deaths. Maternal mortality is the result of causes directly related to pregnancy. A non-maternal death, nonobstetric or unrelated death is defined as a death which occurs during pregnancy or within 42 days following the termination of pregnancy but is considered to be unrelated to pregnancy (e.g., due to injury, suicide, homicide, or malignancy) or its management (Syverson et al. 1991:603608; Public Health Reports 1988:464-471; Rochat 1981:2-13; Koonin, Atrash and Rochat 1988:91-97). No epidemiological or clinical evidence is yet available of an increased risk of non-maternal mortality among pregnant women (Rochat et al. 1988:91-97; Walters 1989:615-616). In this study, the term "non-maternal death" is used instead of "non-obstetric death", "non-related", or "unrelated death".

Non-maternal deaths are not classified in the ninth revision

Senyeong Kao, Associate Professor, School of Public Health, National Defense Medical Center, PO Box 90048-509, Taipei, Taiwan, ROC E-mail : kao@ndmc1.ndmctsgh.edu.tw

Li-Mei Chen, Associate Professor and Chair, Department of Public Health, College of Medicine, Fu-Jen Catholic University, Taipei, Taiwan

Leiyu Shi, Associate Professor, Department of Health Policy and Management, School of Hygiene and Public Health, Johns Hopkins University, USA

Martin C Weinrich, Associate Professor, Department of Epidemiology and Biostatics, University of South Carolina, USA

C Arden Miller, Professor, Department of Maternal and Child Health, School of Public Health, University of North Carolina at Chapel Hill, USA of the International Classification of Disease (ICD-9) (DHHS 1989). Therefore, they are not reported through official vital statistics system or published with a nation's mortality data (Rochat 1981:2-13). Pregnancy-related mortality from "accidental and incidental" causes has historically been excluded from the definition of maternal mortality. That is, the definition of maternal death excludes accidental and incidental causes, while pregnancy-related death includes them. These definitions remain unchanged from the ICD-9 (DHHS 1989; Fortney 1990: 246-248). In addition, most maternal mortality studies do not include nonmaternal deaths. However, as Rochat and associates (Rochat et al. 1981) suggest, maternal mortality studies should compare mortality from maternal with that from non-maternal causes whenever possible. This study identifies the major causes and examines the sociodemographic correlates of non-maternal mortality in Taiwan during the study period.

\section{Methods}

The study determined which Taiwan women aged 10 to 49 had died in the study period regardless of the causes of death entered on the death certificate. Hence, we made copies of the death certificate of all females aged 10 to 49 who died in Taiwan during 1984-88. Family members of those deceased women were interviewed by public health nurses and midwives of local health stations, who received 
pre-interview training to ensure the reliability, consistency, and stability of the interviews. Data collection began annually in July to accumulate the data from the previous year.

A questionnaire protocol including the death certificate was used by the interviewers. Completed questionnaires were examined by the head public-health nurses of local health stations before being sent to the up-level county or city health bureaus in which nursing supervisors were responsible for the second evaluation of the questionnaires. The researchers screened all the questionnaires of female deaths accumulated from county and city health bureaus. The screened pregnancy-related deaths were then reviewed and evaluated by senior obstetricians-gynecologists using a clinically oriented classification scheme, ICD-9-CM (Clinical Modification) (DHHS 1989). In the absence of interviewbased or other additional information, the cause of death was taken from the death certificate.

SAS USAGE software was used for data analysis. The Chisquare analysis (the $\chi^{2}$-test) was employed to examine the socio-demographic correlates of non-maternal mortality.

\section{Results}

There were 27,171 deaths in women aged 10-49 years during 1984-88 in Taiwan. Successful interviews were obtained from family members of 22,121 cases. Interviews on 5,050 deaths were not completed due to the family members' migration, rejection or failure to be contacted after three attempts. The average five-year interview rate was 81.4 percent. Of the 22,121 cases whose family members were interviewed, 520 were known to have died during pregnancy or within 42 days postpartum during the study period.

From the screened 520 pregnancy-related deaths, 274 were clinically reviewed and classified by the obstetriciansgynecologists as due to maternal causes and the other 246 as non-maternally related.

\section{Causes of Death by ICD Codes}

Table 1 lists the five-year distribution of the causes of nonmaternal mortality. All deaths were attributed to one of the causes listed. The causes of non-maternal mortality were taken from the death certificates' original classifications based on the ICD-9. To simplify the presentation and enşure adequate numbers in each cell of Chi-square analysis, some categories were grouped together. Of the 246 non-maternal deaths identified by this study, 95 deaths (38.6 percent) were classified as ICD 001-799 and E960-E989 (diseases and others), 63 (25.6 percent) as ICD E810-E825 (motor vehicle accidents), 42 (17.1 percent) as ICD E858-E949 (other accidents), and 46 (18.7 percent) as ICD E950-E959 (suicide and self-inflicted injury).

Table 1 Distribution of Causes of Non-maternal Deaths Based on Death Certificates $(N=246)$

\begin{tabular}{|c|c|c|c|}
\hline ICD-9 Code & Cause of Death & No. & PMR* \\
\hline $001-799$ & Diseases and Others & 95 & $\overline{38.6}$ \\
\hline \multicolumn{4}{|l|}{ E960-E989 } \\
\hline $001-139$ & Infectious diseases & 7 & 2.8 \\
\hline $140-239$ & Neoplasms & 17 & 6.9 \\
\hline $240-289$ & $\begin{array}{l}\text { Endocrine, nutritional and metabolic } \\
\text { diseases, and immunity disorders }\end{array}$ & 4 & 1.6 \\
\hline $320-389$ & $\begin{array}{l}\text { Inflammatory diseases of the central } \\
\text { nervous system }\end{array}$ & 8 & 3.3 \\
\hline $390-459$ & Diseases of the circulatory system & 17 & 6.9 \\
\hline $460-519$ & Diseases of the respiratory system & 7 & 2.8 \\
\hline $520-579$ & Diseases of the digestive system & 12 & 4.9 \\
\hline $580-629$ & Diseases of the genitourinary system & 5 & 2.0 \\
\hline $710-719$ & Arthropathies and related disorders & 1 & 0.4 \\
\hline $798-799$ & $\begin{array}{l}\text { Sudden death, other ill-defined and } \\
\text { unknown causes }\end{array}$ & 13 & 5.3 \\
\hline E960-E989 & $\begin{array}{l}\text { Homicide and injury purposely inflicted } \\
\text { by other persons }\end{array}$ & 4 & 1.6 \\
\hline E810-E825 & Motor Vehicle Accidents & 63 & 25.6 \\
\hline $\mathrm{E} 812$ & $\begin{array}{l}\text { Other motor vehicle traffic accidents } \\
\text { involving collision with another motor vehicle }\end{array}$ & $e^{10}$ & 4.1 \\
\hline $\mathrm{E} 815$ & $\begin{array}{l}\text { Other motor vehicle traffic accidents } \\
\text { involving collision on the highway }\end{array}$ & 1 & 0.4 \\
\hline E817 & $\begin{array}{l}\text { Non-collision motor vehicle traffic accidents } \\
\text { while boarding or alighting }\end{array}$ & 2 & 0.8 \\
\hline E818 & $\begin{array}{l}\text { Other non-collision motor vehicle } \\
\text { traffic accidents }\end{array}$ & 1 & 0.4 \\
\hline E819 & $\begin{array}{l}\text { Motor vehicle traffic accidents of } \\
\text { unspecified nature }\end{array}$ & 47 & 19.1 \\
\hline E823 & $\begin{array}{l}\text { Other motor vehicle non-traffic accidents } \\
\text { involving collision with stationary object }\end{array}$ & 2 & 0.8 \\
\hline E858-E949 & Other Accidents & 42 & 17.1 \\
\hline E858-E869 & $\begin{array}{l}\text { Accidental poisoning by other drugs, } \\
\text { alcohol, gas, agricultural and horticultural } \\
\text { chemical and pharmaceutical preparations }\end{array}$ & 15 & 6.1 \\
\hline $880-E 899$ & Accidents by falls and fire & 7 & 2.8 \\
\hline 910-E949 & $\begin{array}{l}\text { Accidental drowning and submersion; } \\
\text { other accidents }\end{array}$ & 20 & 8.1 \\
\hline $950-E 959$ & Suicide and Self-inflicted Injury & 46 & 18.7 \\
\hline 950 & $\begin{array}{l}\text { Suicide and self-inflicted poisoning by } \\
\text { solid or liquid substances }\end{array}$ & 39 & 15.9 \\
\hline 951 & $\begin{array}{l}\text { Suicide and self-inflicted poisoning } \\
\text { by gases in domestic use }\end{array}$ & 1 & 0.4 \\
\hline 953 & $\begin{array}{l}\text { Suicide and self-inflicted injury by hanging, } \\
\text { strangulation and suffocation }\end{array}$ & 6 & 2.4 \\
\hline
\end{tabular}




\section{Diseases and others (ICD 001-799, E960-E989)}

Of the 95 deaths associated with diseases and others, the four chief causes were neoplasms (ICD 140-239), diseases of the circulatory and digestive systems (ICD 390-459 and ICD 520-579), and sudden deaths, and unknown causes (ICD 798-799). Neoplasms (all malignant) and circulatory diseases were the major causes of death from diseases, each accounting for 17 deaths, and each representing 6.9 percent of the total 246 non-maternal deaths. Sudden deaths and unknown causes accounted for 13 deaths and digestive diseases accounted for 12 deaths, representing 5.3 percent and 4.9 percent of the total 246 non-maternal deaths, respectively.

\section{Motor vebicle accidents (ICD E810-E825)}

of the 63 deaths associated with motor vehicle accidents, motor vehicle traffic accidents of unspecific nature (ICD E819) were the most frequent cause of non-maternal deaths among pregnant women investigated, accounting for 47 deaths, representing 19.1 percent of the total 246 nonmaternal deaths. Collision with another motor vehicle (ICD E812) accounted for 10 deaths, representing 4.1 percent of all the non-maternal deaths.

\section{Other accidents (ICD E858-E949)}

Of the 42 deaths associated with other accidents, accidental drowning and submersion (ICD E910-E949) accounted for 20 deaths, representing 8.1 percent of all non-maternal deaths; accidental poisoning (ICD E858-E869) accounted for another 15 deaths, representing 6.1 percent of all nonmaternal deaths; and accidents by falls and fire (ICD E880E899) accounted for another 7 deaths, representing 2.8 percent of the total non-maternal deaths.

\section{Suicide and self-inflicted injury (ICD E950-E959)}

Suicide by taking a poisoned substance (ICD 5950 ) was the second most significant cause of non-matern: : mortality in this study, accounting for 39 deaths and rę resenting 15.9 percent of the total 246 non-maternal deaths.

Suicide by hanging, strangulation and suffocation (ICD E953) accounted for another 6 deaths, representing 2.4 percent of all non-maternal deaths.

\section{Leading Causes and Cause-Specific Mortality Rates}

Most of the 246 non-maternal deaths, excluding unrelated diseases, were attributed to unintentional and intentional injuries. Most of the unintentional injuries were due to automotive accidents and other accidents. The other injuries were intentional; most were due to suicide.

Table 2 lists the leading causes and their cause-specific mortality rates of non-maternal deaths. In this study, motor vehicle accidents, suicides, and other accidents were the three most frequently specified causes of non-maternal mortality related to injuries. These three injury-related causes accounted for 61.4 percent of all non-maternal deaths. The remaining cases of non-maternal deaths were attributed to a variety of diseases, unknown causes, and homicides. No significant trends were found in the leading causes of nonmaternal mortality in Taiwan during the five-year study period.

As Table 2 illustrates, the five-year cause-specific mortality rate per 100,000 live births was 3.76 for motor accidents; 2.75 for suicides; 2.51 for other accidents; and 5.68 for diseases and others.

Table 2 Leading Causes and Cause-specific Mortality Rates of Non-maternal Deatbs

\begin{tabular}{|c|c|c|c|c|c|c|}
\hline \multicolumn{2}{|c|}{ Year.s.s } & \multirow{2}{*}{$\begin{array}{r}\text { Motor Accidents } \\
11(17.5)\end{array}$} & \multirow{2}{*}{$\frac{\text { Other Accidents }}{6(14.3)}$} & \multirow{2}{*}{$\frac{\text { Suicides }}{14(30.4)}$} & \multirow{2}{*}{$\frac{\text { Disease/others }}{25(26.3)}$} & \multirow{2}{*}{$\frac{\text { Total }}{56(22.8)}$} \\
\hline 1984 & Deaths (\%) & & & & & \\
\hline & $\operatorname{CSMR}^{*}$ & 2.98 & 1.63 & 3.80 & 6.78 & 15.18 \\
\hline \multirow[t]{2}{*}{1985} & Deaths (\%) & $13(20.6)$ & $8(19.1)$ & $9(19.6)$ & $13(13.7)$ & $43(17.5)$ \\
\hline & $\mathrm{CSMR}^{*}$ & 3.79 & 2.33 & 2.62 & 3.79 & 12.54 \\
\hline \multirow[t]{2}{*}{1986} & Deaths (\%) & $15(23.8)$ & $8(19.1)$ & $12(26.1)$ & $20(21.1)$ & $55(22.4)$ \\
\hline & $\mathrm{CSMR}^{*}$ & 4.90 & 2.61 & 3.92 & 6.53 & 17.95 \\
\hline \multirow[t]{2}{*}{1987} & Deaths (\%) & $11(17.5)$ & $11(26.2)$ & $6(13.0)$ & $21(22.1)$ & $49(19.9)$ \\
\hline & $\mathrm{CSMR}^{*}$ & 3.51 & 3.51 & 1.92 & 6.70 & 15.64 \\
\hline \multirow[t]{2}{*}{1988} & Deaths (\%) & $13(20.6)$ & $9(21.4)$ & $5(10.9)$ & $16(16.8)$ & $43(17.5)$ \\
\hline & CSMR* & 3.80 & 2.63 & 1.46 & 4.68 & 12.56 \\
\hline \multicolumn{2}{|c|}{ Total Deaths (\%) } & $63(25.6)$ & $42(17.1)$ & $46(18.7)$ & $95(38.6)$ & $246(100.0)$ \\
\hline & $\operatorname{CSMR}^{*}$ & 3.76 & 2.51 & 2.75 & 5.68 & 14.70 \\
\hline
\end{tabular}

${ }^{n . s}$ Non-significant

${ }^{*}$ Cause-specific mortality rate per 100,000 live births; Total live births for 1984-88 $=1,673,608$ (statistics adopted from DHEY 1994) 
Table 3 Leading Causes of Non-maternal Mortality by Socio-demographic Characteristics

\begin{tabular}{|c|c|c|c|c|c|c|}
\hline $\begin{array}{l}\text { Socio-demographic } \\
\text { Characteristics }\end{array}$ & & $\begin{array}{r}\text { Motor Accidents } \\
\text { Deaths (\%) } \\
\end{array}$ & $\begin{array}{r}\text { Other Accidents } \\
\text { Deaths }(\%)\end{array}$ & $\begin{array}{r}\text { Suicides } \\
\text { Deaths (\%) }\end{array}$ & $\begin{array}{r}\text { Disease/Others } \\
\text { Deaths }(\%)\end{array}$ & $\begin{array}{r}\text { Total } \\
\text { Deaths (\%) } \\
\end{array}$ \\
\hline Urbanization ${ }^{n . s}$ & & 63 & 42 & 46 & 95 & 246 \\
\hline Municipal City & & $8(12.7)$ & $6(14.3)$ & $2(4.4)$ & $13(13.7)$ & $29(11.8)$ \\
\hline County/City & & $11(17.5)$ & $6(14.3)$ & $8(17.4)$ & $26(27.4)$ & $51(20.7)$ \\
\hline Ltban Township & & $16(25.4)$ & $9(21.4)$ & $9(19.6)$ & $15(15.8)$ & $49(19.9)$ \\
\hline Rural Township & & $28(44.4)$ & $21(50.0)$ & $27(58.7)$ & $41(43.2)$ & $117(47.6)$ \\
\hline Age $^{* * *}$ & & 63 & 42 & 46 & 95 & 246 \\
\hline Under 20 & & $4(6.4)$ & $2(4.8)$ & $8(17.4)$ & $1(1.1)$ & $15(6.1)$ \\
\hline $20-24$ & & $23(36.5)$ & $23(54.8)$ & $19(41.3)$ & $25(26.3)$ & $90(36.6)$ \\
\hline $25-29$ & & $27(42.9)$ & $12(28.6)$ & $16(34.8)$ & $44(46.3)$ & $99(40.2)$ \\
\hline 30 and Older & & $9(14.3)$ & $5(11.9)$ & $3(6.5)$ & $25(26.3)$ & $42(17.1)$ \\
\hline Marital Status ${ }^{n-s}$ & & 63 & 42 & 46 & 95 & 246 \\
\hline Married & & $56(88.9)$ & $36(85.7)$ & $37(80.4)$ & $83(87.4)$ & $212(86.2)$ \\
\hline Non-married & & $7(11.1)$ & $6(14.3)$ & $9(19.6)$ & $12(12.6)$ & $34(13.8)$ \\
\hline Marriage Age* & & 58 & 33 & 37 & 83 & 211 \\
\hline Under 20 & & $14(24.1)$ & $8(24.2)$ & $15(40.5)$ & $10(12.1)$ & $47(22.3)$ \\
\hline $20-24$ & & $33(56.9)$ & $19(57.6)$ & $16(43.2)$ & $46(55.4)$ & $114(54.0)$ \\
\hline 25 and Older & & $11(19.0)$ & $6(18.2)$ & $6(16.2)$ & $27(32.5)$ & $50(23.7)$ \\
\hline Occupation $^{\text {nss }}$ & & 63 & 42 & 46 & 95 & 246 \\
\hline Unemployed & & $32(50.8)$ & $26(61.9)$ & $29(63.0)$ & $54(56.8)$ & $141(57.3)$ \\
\hline Employed & & $31(49.2)$ & $16(38.1)$ & $17(37.0)$ & $41(43.2)$ & $105(42.7)$ \\
\hline Years of Education* & & 63 & 42 & 46 & 95 & 246 \\
\hline $0-6$ & & $20(31.8)$ & $10(23.8)$ & $21(45.7)$ & $34(35.8)$ & $85(34.6)$ \\
\hline $7-9$ & & $27(42.9)$ & $15(35.7)$ & $18(39.1)$ & $26(27.4)$ & $86(35.0)$ \\
\hline 10 and More & & $16(25.4)$ & $17(40.5)$ & $7(15.2)$ & $35(36.8)$ & $75(30.5)$ \\
\hline Place of Death* & & 63 & 42 & 45 & 94 & 244 \\
\hline Government Hospital & - & $7(11.1)$ & $5(11.9)$ & $3(6.7)$ & $19(20.2)$ & $34(13.9)$ \\
\hline Private Hospital/Clinic & & $25(39.7)$ & $14(33.3)$ & $12(26.7)$ & $38(40.4)$ & $89(36.5)$ \\
\hline Home/Others & & $31(49.2)$ & $23(54.8)$ & $30(66.7)$ & $37(39.4)$ & $121(49.6)$ \\
\hline
\end{tabular}

"p<0.05( $\left.\chi^{2}\right) ;{ }^{* * *} p<0.001\left(\chi^{2}\right) ;{ }^{n . s}$ Non-significant

This study examines the indicators among sociodemographic characteristics and places of death to determine their association with the leading causes of non-maternal mortality. Table 3 lists the leading causes of non-maternal mortality during the study period by socio-demographic characteristics and place of death. Women at the lowest level of urbanization (rural townships) had a somewhat (but not significantly) higher percentage of deaths from suicide than those at other levels of urbanization. Suicides were significantly higher in percentage among young women and women who married young (under 20), and those with low level of education.

The percentage of suicides was slightly higher among nonmarried women (including unmarried, single, divorced, separated, and widowed women); however, the difference was insignificant. Women who died of diseases and other causes were more likely to have hospitals or clinics as places of death (more than 60 percent), whereas most (half or more than half) of the other three leading causes occurred at home or other places.

\section{Discussion}

\section{Distinction between Maternal and Non-maternal Deaths}

The distinction between maternal deaths and non-maternal deaths is difficult to make with certainty. Some deaths from external causes may actually be attributable to the pregnancy itself. An example in the study by Fortney and associates (Fortney et al. 1986:134-138) illustrates the case of a young, unmarried woman who was murdered by her family, who preferred this drastic measure to the shame of a premarital pregnancy. It is likely that many homicides, and probably most suicides of pregnant or recently-pregnant women are in some way related to the pregnancy. 
Accidents might also be considered in this light (Fortney 1990:246-248). Other situations proposed by Dorfman (Dorfman 1990:317-323) also demonstrate the increasing difficulty in distinguishing maternal from non-maternal deaths.

"What if homicide cases were perpetrated by jealous lovers, or a drug-crazed thief looking for an easy hit? What if a bathtub electrocution occurred because advanced pregnancy threw the woman off her balance?

What if postpartum depression pushed the suicidal woman over the brink?

Are these pregnancy-related deaths?"

In some cases, the study had difficulty in defining a death as maternal or non-maternal either because of lack of available information, or because of an uncertainty in the pathogenesis of the factors leading to the maternal deaths. In these uncertain cases, this study adopted the position of favoring non-maternal cause of mortality over maternal cause in order not to favorably affect the maternal mortality. Restated, when there was either more than one possible cause of death or insufficient evidence on the basis of available information, priority was given to non-maternal causes.

\section{Intentional and Unintentional Injuries}

Deaths from injury accounted for most of the non-maternal deaths. In the United States, intentional and unintentional injuries are a leading cause of death among reproductiveage women (Rochat et al. 1988:91-97; Centers for Disease Control 1986:118; Koonin, Atrash and Lawson 1991; Sachs et al. 1987:667-672; Varner 1989:555-562).

The findings of this study correspond with the reports that motor vehicle accidents, other accidents and suicides were the leading causes of non-maternal deaths (Table 1). Deaths from injury considered in this study accounted for more than 60 percent of all the 246 nonmaternal deaths (Table 2).

Trauma remains a persistent cause of preventable nonmaternal deaths in Taiwan which reveals the necessity of continued public education as well as legislation for mandatory safety restraints on automobiles. This also suggests that considerable room for improvement exists in the field of education of patients, and of health care professionals who routinely care for patients with complicated obstetric problems (Varner 1989:555-562).

\section{Suicides}

Overall, approximately one-fifth of the total 246 nonmaternal deaths were attributed to suicides: these were reported and classified on the death certificates as nonmaternal deaths during the five-year study period (Table 2). We believe that non-maternal deaths from suicides were substantially under-reported. Based on the results of the interviews, at least 9 additional suicide cases were misclassified according to the original ICD codes: 7 deaths as "other accidents" and 2 deaths as "diseases or others". That is, at least 55 (22.4 percent) women died from suicide rather than the official 46 (18.7 percent) during the fiveyear study period. Thus, the study estimates that the official reports by death certificates detected no more than 80 percent of the deaths $\left\{[1-(9 / 46)]^{*} 100\right.$ percent $\}$ of pregnant women dying from suicide. This is based only on confirmed cases and is probably a minimal estimate. We also suspect that pregnancy status may be determined for women dying from suicide but the information is not shared in official reports.

Suicide is alarmingly the second most common traumatic cause of non-maternal deaths. In addition to the physical stress, the emotional, social and financial pressures of pregnancy, particularly an unplanned or unwanted one, must always be acknowledged (Varner 1989:555-562; Alauddin 1986:13-21).

Some of the suicides were considered preventable because health care providers had failed to appreciate significant preceding psychiatric disorders.

\section{Other Accidents}

Injuries from other accidents were the third leading cause of the non-maternal deaths among pregnant women investigated during the five-year study period (Table 2). The study suspects that non-maternal deaths under this classification were considerably overreported. Quite surprising was the frequency of deaths among pregnant women from "accidents" such as falls, drowning 
(submersion), and poisoning: Many social, cultural, religious, emotional or practical reasons account for not classifying deaths as suicides. Women who commit suicide may often have their deaths classified as "accidents" to avoid embarrassing the surviving family or for other traditional Chinese reasons. The extent of this type of underreporting can be considerable.

\section{Motor Vehicle Accidents}

Injuries from motor vehicle accidents were the most frequent cause of non-maternal mortality among pregnant women investigated (Table 2). This certainly allows re-emphasis of the often heard prescriptions against driving without seatbelts and driving when intoxicated. In addition, the three-point hamess allows for dissipation of crash energy over the chest wall and pelvis (Kemmerer 1987:574-575). All motor-vehicle occupants, especially pregnant women, should always wear three-point restraints.

Based on the study by Varner (1989:555-562), the documented number of motor vehicle accident deaths during the study period represents only a small fraction of the actual total, because in Taiwan motor vehicle accident deaths are the most common cause of deaths among women of reproductive age (DHEY 1994).

\section{Diseases and Others}

Of the approximately two-fifths of non-maternal deaths resulting from diseases and others, the major cause was malignant neoplasms which are thought to be related only temporarily to pregnancy.

Specific malignant diseases represent many of those commonly found in women of reproductive age (DHEY 1994). The remaining deaths resulted from diseases of the circulatory and digestive systems, and various other diseases or disorders (Table 1).

\section{The Role of Care Providers}

Obstetric care providers have a unique responsibility and opportunity to prevent deaths resulting from personal, social and behavioral factors through counseling and health education. Simple measures such as recommending seatbelts for pregnant women have been reported to have reduced maternal injuries and deaths from vehicle accidents. Detection of battering during pregnancy and early counseling of those women who are battered may also contribute to prevention of deaths from such causes (Rochat et al. 1988:91-97).

In conclusion, the approach of systematically identifying cases of non-maternal mortality adapted in this study is the first of its kind in the health history of Taiwan. Its findings and suggestions may have important implications for future legislation in Taiwan.

\section{Acknowledgments}

This study was supported by a specific grant from the Department of Health, Executive Yuan of the ROC. We would like to thank Dis ME Samuels and SL Baker for their time and valuable comments on an earlier version of this article. We acknowledge substantial contributions during early stages of this work by Drs C-S Yin, J-H Yan and Y-F Yang, in Department of OB-GYN, Tri-Service General Hospital, Taipei.

\section{References}

Alauddin, M. 1986. Maternal mortality in rural Bangladesh: the Tangail district. Studies in Family Planning 17:13-21.

Centers for Disease Control (CDC). 1986. Annual summary 1984: reported morbidity and mortality in the United States. MMWR 33:118.

Department of Health, the Executive Yuan (DHEY). 1994. Health and vital statistics, Taiwan Area, ROC 1993: 1. General health statistics, Taiwan Area, ROC 1993; 2. Vital statistics, Taiwan Area, ROC 1993. Taiwan: Chen-Chung Book Company Press.

US Department of Health and Human Services (DHHS). 1989. The International Classification of Diseases, 9th revision, clinical modification: ICD-9-CM, third edition. Volume 1: Diseases tabular list. DHHS Publication No. (PHS) 89-1260.

Dorfman, SF. 1990. Maternal mortality in New York city, 1981 to 1983. Obstetric Gynecology 76:317-323.

Fortney, JA. 1990. Implications of the ICD-10 definitions related to death in pregnancy, childbirth or the puererium. World Health Statistical Quarterly 43:246-248.

Fortney, JA, I Susanti, and S Gadalla et al. 1986. Reproductive mortality in two developing countries. American Journal of Public Health 76:134-138.

Kemmerer, DL. 1987. Toward prevention of maternal mortality (letter to the Editor). New England Journal of Medicine 317:574-575.

Koonin, LM, HK Atrash and HW Lawson. 1991. Maternal mortality surveillance, United States, 1979-1986. MMWR 40:SS-1.

Koonin, LM, HK Atrash and RW Rochat. 1988. Maternal mortality surveillance, United States, 1980-1985. MMWR 37:SS-5.

Public Health Reports. 1988. Standard terminology for reporting of reproductive health statistics in the United States. Public Healtb Report 103:464-471.

Rochat, RW. 1981. Maternal mortality in the United States of America. World Health Statistical Quarterly 34:2-13. 
Rochat, RW, GL Rubin and R Selik et al. 1981. Changing the definition of maternal mortality: a new look at the postpartum interval (letter to the Editor) Lancet i:831.

Rochat, RW, LM Koonin and HK Atrash et al. 1988. Maternal mortality in the United States: report from maternal monality collaborative. Obstet. Gynecol. 72:91-97.

Sachs, BP, DA Brown and SG Driscoll et al. 1987. Maternal mortality in Massachusetts: trends and prevention. New England Journal of Medicine 316:667-672
Syverson, CJ, W Chavkin and HK Atrash et al. 1991. Pregnancy- related mortality in New York city, 1980 to 1984: causes of death and associated risk factors. American Journal of Obstetric Gynecology 164:603-608

Varner, MW. 1989. Maternal mortality in Iowa from 1952 to 1986. Surgery, Gynecology \& Obstetrics 168:555-562.

Walters, WAW. 1989. Maternal mortality. The Medical Journal of Australia 151:615-616. 